\section{Cahiers franco-canadiens de l'Ouest}

\section{Construire une maison}

\section{Gisèle Fréchette-Beaudry}

Autour de Gabrielle Roy

URI : https://id.erudit.org/iderudit/1029458ar

DOI : https://doi.org/10.7202/1029458ar

Aller au sommaire du numéro

Éditeur(s)

Presses universitaires de Saint-Boniface (PUSB)

ISSN

0843-9559 (imprimé)

1916-7792 (numérique)

Découvrir la revue

Citer cet article

Fréchette-Beaudry, G. (2014). Construire une maison. Cahiers franco-canadiens de l'Ouest, 26(1-2), 67-69. https://doi.org/10.7202/1029458ar

Tous droits réservés (c) Centre d'études franco-canadiennes de l'Ouest (CEFCO) et Presses universitaires de Saint-Boniface (PUSB), 2015

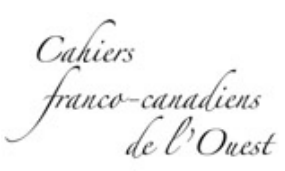

Ce document est protégé par la loi sur le droit d'auteur. L’utilisation des services d'Érudit (y compris la reproduction) est assujettie à sa politique d'utilisation que vous pouvez consulter en ligne.

https://apropos.erudit.org/fr/usagers/politique-dutilisation/ 


\title{
Construire une maison
}

Gisèle FRÉCHETTE-BEAUDRY

\author{
J'habite une petite maison \\ Dans la maison de mes parents. \\ J'habite une petite maison \\ Entre l'entrée et le salon. \\ Elle est faite de bouts de chiffon \\ De petits meubles et de vieux \\ cartons. \\ Tapissée de papier d'illusion \\ Je m'y sens bien \\ Il y fait bon...
}

Gérard Lenorman*

Depuis toujours, $\mathrm{j}$ ' affectionne la petite maison, surtout la construction de celle-ci. Ne serait-ce que pour le plaisir de me remémorer et de ressentir à nouveau le frisson délectable que j'éprouve lorsque je me livre à cette création, je vous fais part de mes aventures. Dès ma tendre enfance, j'ai construis des maisons utilisant différents matériaux. Jeune enfant, je passais des heures à bâtir des abris où je me réfugiais dans mon petit monde. J'amassais tout ce qui pouvait servir de matériaux de construction pour bâtir mon gîte. À la table et aux chaises de cuisine s'ajoutaient les couvertures de lit, les serviettes, les serviettes pour essuyer la vaisselle et un peu de corde, le tout retenu par des épingles à linge ( $c^{\prime}$ est peut-être de là que me vient le goût d'accrocher la lessive sur la corde à linge). Et quelle joie aussi lorsqu'un appareil ménager de taille était livré chez nous! Je m'appropriais aussitôt la grande boîte de carton. Des fenêtres y étaient taillées ainsi qu'une porte; la peinture était étendue et les petits rideaux étaient installés. Elle était belle, ma maison!

* «J'habite une petite maison», chanson extraite de l'album La clairière de l'enfance paru en 1980. 
Je les bâtissais à l'intérieur et à l'extérieur, en été et en hiver. Forteresses fabriquées de branches feuillues et enclos creusés dans la neige. Ah, la belle époque!

Devenue «grande» à l'âge adulte, je suis demeurée éprise par la fascination pour la maison. La maison prise en photographie, en croquis, en tapisserie, en aquarelle; elle m'attire et $\mathrm{m}$ 'invite à la découverte! Même une maison abandonnée dans un champ de blé, une maison en détresse, a toute une histoire à raconter!

Jeune maman, je me suis lancée dans la réalisation d'une maison de poupée (pour mes enfants, bien sûr!). J'ai donné libre cours à ma fantaisie. Quel beau défi! Quelle joie de retomber dans le monde lilliputien! Je me retroussais les manches -j'avais la chance de construire, toujours et encore! Qui n'a pas bâti une maison faite de blocs en bois ou en plastique, pour ensuite la démolir sous les éclats de rire? Et, à Noël, il y a la fameuse maison faite de biscuits au gingembre. Projet non seulement enchanteur, mais délicieux! Comment ne pas être emballée par une telle activité!

Je demeure très intriguée lorsque je passe devant une maison en construction. La maison se dessine et monte petit à petit. On entend et on voit le chef-d'œuvre naître. Dans la nature, les oiseaux, les araignées, les animaux bâtissent leur maison dans le silence. Ces maisons sont faites de matériaux naturels. Le petit nid, la tanière, même la toile d'araignée. C'est génial!

J'ai toujours aimé le concept de bâtir une maison dans un arbre. Jeune fille, je rêvais d'une maison à moi toute seule, construite dans un arbre majestueux. Ça serait mon coin spécial, où je pourrais aller me perdre dans mes pensées. Composer avec les éléments pour ensuite transposer les expériences de la vie et en livrer les émotions! Construire la maison sans détruire l'arbre; embrasser la forme de l'arbre; y ajouter une balustrade et des colonnes sans l'usage de clous. L'arbre serait un chêne; il abriterait les oiseaux, les écureuils et moi!

Eh bien, je rêve... je rêve et j'ai toujours la chance de me lancer dans la fabrication de petites maisons, soit avec les petits enfants, soit dans l'écriture... Je compose... Je construis 
des poèmes, des phrases... Telle la maison, la phrase est construite selon un certain schéma. À la base, on y retrouve une structure bien fondée, une pensée précise et claire érigée sur une bonne fondation. Le choix de matériaux de construction, de l'expression exacte et voulue contribue à l'élévation de la charpente. Elle prend forme, se définit. La chaumière devient chimère, l'illusion, le chiffon, l'étoffe, une pensée - une création! «Je m'y sens bien... il y fait bon».

Native de Saint-Boniface, Gisèle Fréchette-Beaudry, inspirée par sa famille, son quotidien, les plaines et ses gens, ses voyages et des paysages, a publié à quelques reprises des œuvres de poésie et de prose, ainsi que des haïkus. Une de ses nouvelles a été primée dans le cadre d'un concours de RadioCanada; ses textes ont également été publiés dans les Cahiers franco-canadiens de l'Ouest, dans des ouvrages collectifs tels que Sillons: hommage à Gabrielle Roy, des anthologies aux Dossiers d'Aquitaine (France) et, récemment, dans le recueil de haïkus sur une même écorce, sous la direction de Bertrand Nayet. 